\title{
RELATIONSHIPS BETWEEN MICROSTRUCTURAL PARAMETERS AND TIME-DEPENDENT MECHANICAL PROPERTIES OF A NEW NICKEL BASED SUPERALLOY AD730 ${ }^{\mathrm{TM}}$
}

\author{
Louis Thébaud ${ }^{1,2}$, Patrick Villechaise ${ }^{2}$, Jonathan Cormier $^{2}$, Florence Hamon ${ }^{2}$, Coraline Crozet ${ }^{1}$, Alexandre Devaux ${ }^{1}$, Jean-Michel \\ Franchet $^{3}$, Anne-Laure Rouffié ${ }^{3}$, Antoine Organista ${ }^{4}$ \\ ${ }^{1}$ Aubert \& Duval, Site des Ancizes, Research and Development, BP1, 63770, Les Ancizes, France \\ ${ }^{2}$ Institut Pprime, UPR CNRS 3346, Physics and Mechanics of Materials Department, ISAE-ENSMA, BP 40109, 86961, Futuroscope- \\ Chasseneuil Cedex, France \\ ${ }^{3}$ Safran SA, SafranTech - Materials \& Process Division, Rue des Jeunes Bois - Châteaufort - CS 80112, 78772, Magny-Les-Hameaux, \\ France \\ ${ }^{4}$ Safran Turbomeca, Avenue Joseph Szydlowski, 64511, Bordes, France
}

Keywords: AD730 ${ }^{\mathrm{TM}}$, cast \& wrought superalloys, high temperatures, creep, dwell-fatigue, inter/intra granular properties, oxidation

\begin{abstract}
High temperature viscoplastic properties of the new nickel-based superalloy $\mathrm{AD} 730^{\mathrm{TM}}$ have been investigated, under creep and dwell-fatigue loading conditions. The aim of this study is to evaluate the influence of several microstructural parameters on these properties. Three microstructures have then been tested in creep and dwell-fatigue, at $700{ }^{\circ} \mathrm{C}$ and $850{ }^{\circ} \mathrm{C}$ : a Fine Grain microstructure, a Coarse Grain one and a Single Crystalline microstructure.

The creep-controlling parameters at $850{ }^{\circ} \mathrm{C}$ are the grain size and intragranular $\gamma^{\prime}$ volume fraction, whereas at $700{ }^{\circ} \mathrm{C}$, these controlling parameters depend on the applied stress. Indeed, depending on the applied stress, changes of creep deformation mechanisms have been evidenced for both the Fine and Coarse Grain microstructures.

Dwell-fatigue tests revealed that depending on the applied stress, the influence of the unloading phase may have a beneficial impact on the overall behavior. An attempt is proposed to explain this phenomenon, by highlighting the appearance of a "negative plastic deformation" occurring during the unloading phase in dwellfatigue tests at high maximum applied stresses.
\end{abstract}

\section{Introduction}

The current tendency in developing new aero-engines is to increase their efficiency and to reduce their $\mathrm{NO}_{\mathrm{x}}$ emissions. One way to achieve that is to increase their operating temperatures. Hence, nickel-based superalloys, already widely used for the rotating parts of the hottest sections of such aero-engines, have to be able to withstand higher temperatures, above $700{ }^{\circ} \mathrm{C}$ in the rim sections of high pressure turbine disks for instance, to meet these requirements. In this range of temperatures, traditional superalloys, such as Alloy 718, cannot be used anymore due to the coarsening of the strengthening $\gamma^{\prime \prime}$ phase above $650{ }^{\circ} \mathrm{C}$ that contributes to a decrease of mechanical properties [1,2].

$\mathrm{AD} 730^{\mathrm{TM}}$ is a new nickel-based superalloy, designed by Aubert \& Duval for turbine disks or seal rings applications for instance. One of the main objectives of this development is the optimization of the high temperature capability combined with a moderate manufacturing cost [3-6].

The aero-engine components that could be considered for the introduction of the $\mathrm{AD} 730^{\mathrm{TM}}$ are subjected to several types of loading during service operation that induce creep, fatigue and any combinations of these mechanisms. Depending on the zone of the component, these complex interactions will depend on the temperature, on the local applied stress and on the possible oxidation coupling effect. For $\gamma / \gamma^{\prime}$ superalloys, these interactions have consequences in terms of mechanical behavior and durability [7-12]. Clearly the use of pure creep and pure fatigue tests does not permit to completely describe the mechanical behavior of these materials subjected to more representative cycles. Moreover, the durability could not be simply predicted by using the number of cycles to failure in fatigue and the time to failure in creep. In this context, the aim of this paper is to investigate the behavior and the resistance of the $\mathrm{AD} 730^{\mathrm{TM}}$ with a special focus on the dwell-fatigue loadings. In this field the viscoplastic properties of the alloy are of prime importance.

These properties are highly dependent on microstructural parameters such as grain size, grain boundary morphology, size and morphology of the strengthening phase $\gamma^{\prime}$. Three different microstructures have been used for the present work to study these factors. A special focus will be paid on the influence of the applied stress in creep and dwell-fatigue loading conditions. Moreover, some specificities in dwell-fatigue behavior, already seen but not analyzed in a previous study [13], will be discussed.

\section{Experiment procedure}

\section{$\underline{\text { Material and characterization }}$}

Two polycrystalline microstructures and one single crystalline microstructure have been studied, all coming from the same ingot of AD730 ${ }^{\mathrm{TM}}$ provided by Aubert \& Duval (Les Ancizes, France). The chemical composition is given by Table I. The polycrystalline material was supplied as an $87 \mathrm{~mm}$ cylindrical forged bar. Blanks were cut along the longitudinal direction, at mid-radius, prior to heat treatment. Two kinds of microstructures were studied. The first one, designed for creep resistance, presents a homogeneous coarse grain distribution, with an average grain size of about 350 $\mu \mathrm{m}$. The second one is a fine grain microstructure, developed for high tensile strength, low cycle fatigue, and disk burst resistance (average grain size: $10 \mu \mathrm{m}$ ). These microstructures will be denoted in the paper as "Coarse Grain" (CG) and "Fine Grain" (FG) microstructures, respectively. CG microstructure was obtained by a supersolvus heat treatment composed of two solution treatments: $2 \mathrm{~h}$ at $1120{ }^{\circ} \mathrm{C} / 70{ }^{\circ} \mathrm{C} \cdot \mathrm{min}^{-1}+4 \mathrm{~h} / 1080{ }^{\circ} \mathrm{C} /$ Air Quench (AQ) followed by a two-step aging: $4 \mathrm{~h} / 800{ }^{\circ} \mathrm{C} / \mathrm{AQ}+16 \mathrm{~h} / 760{ }^{\circ} \mathrm{C} / \mathrm{AQ}$, while FG microstructure was obtained by one solution treatment followed by one aging: $4 \mathrm{~h} / 1080{ }^{\circ} \mathrm{C} / \mathrm{AQ}+8 \mathrm{~h} / 730{ }^{\circ} \mathrm{C} / \mathrm{AQ}[6]$. 
Table I. Chemical composition (in wt. \%) of AD730 ${ }^{\mathrm{TM}}$ nickel-based superalloy.

\begin{tabular}{ccccccccccccc}
\hline Element & Ni & C & Cr & Mo & W & Al & Co & Ti & Nb & Fe & B & Zr \\
\hline Wt. \% & Balance & $<0.02$ & 16 & 3 & 2.7 & 2.3 & 8.5 & 3.5 & 1.1 & 4 & 0.01 & 0.03 \\
\hline
\end{tabular}

Table II. Characteristics of the three microstructures (N.O. = Not Observed)

\begin{tabular}{cccccc}
\hline \multirow{2}{*}{ Microstructure } & Grain & \multicolumn{4}{c}{ Average $\boldsymbol{\gamma}^{\prime}$ Precipitation Size / Volume Fraction } \\
\cline { 3 - 6 } & Size & Primary & Coarse Secondary & Fine Spherical Secondary & Tertiary \\
\hline Fine Grain & $10 \mu \mathrm{m}$ & $1 \mu \mathrm{m} / 15 \%$ & $\mathrm{X}$ & $40 \mathrm{~nm} / 25 \%$ & N.O. \\
Coarse Grain & $350 \mu \mathrm{m}$ & $\mathrm{X}$ & $300 \mathrm{~nm} / 12 \%$ & $35 \mathrm{~nm} / 20 \%$ & N.O. \\
Single Crystals & $\mathrm{X}$ & $\mathrm{X}$ & $300 \mathrm{~nm} / 12 \%$ & $35 \mathrm{~nm} / 20 \%$ & N.O. \\
\hline
\end{tabular}
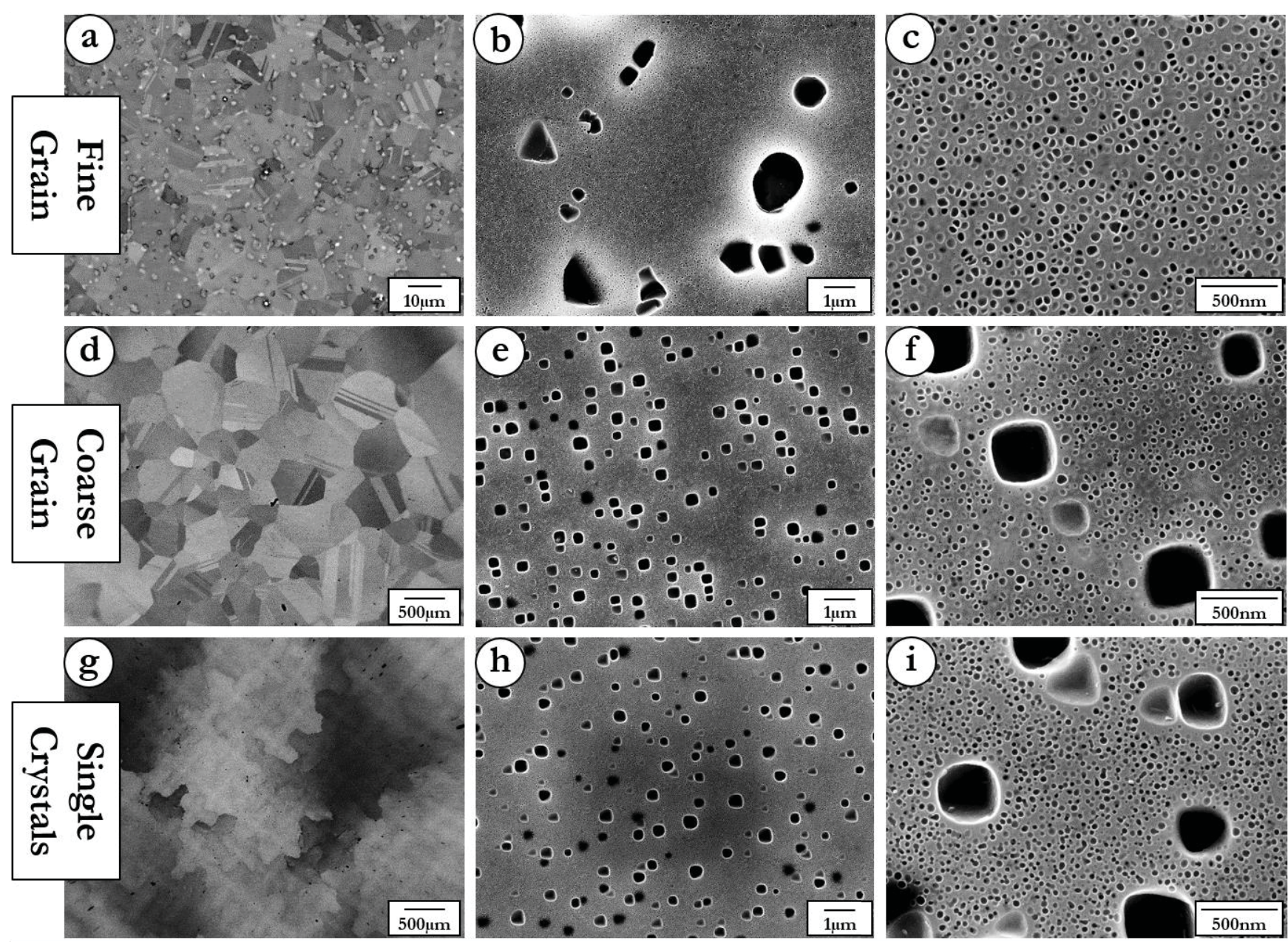

Figure 1. Granular microstructure observed in SEM back-scattered electron mode (a, d, g), and coarse and fine $\gamma^{\prime}$ precipitation (b, e, $\mathbf{h}$ and c, f, i respectively) observed using the secondary electron mode for the FG microstructure (a, b, c), CG microstructure (d, e, f) and the SX microstructure $(\mathbf{g}, \mathbf{h}, \mathbf{i})$. Note that boundaries observed in $(\mathbf{g})$ correspond to low angle boundaries (crystallographic misorientation less than three degrees between each domain).

The single crystalline structure (SX) has been specifically elaborated by SNECMA-SAFRAN Group for this study. These bars were casted along a $\sim[001]$ crystallographic orientation. The same supersolvus heat treatment used for the CG microstructure has been performed on these single crystalline bars in order to be able to compare the grain size with the same precipitation distribution.

Microstructural investigations have been made on etched specimens using a JEOL $7000 \mathrm{~F}$ field emission gun scanning electron microscope (FEG-SEM). Figure 1 presents typical images at three different magnifications for each microstructure to illustrate the multiscale aspects of these materials, from the grain structure to the finest $\gamma^{\prime}$ precipitation. A quantitative analysis performed on several images leads to the mean characteristics summarized in Table II.

FG microstructure is composed of primary $\gamma^{\prime}$ with an average size of about $1 \mu \mathrm{m}$, and fine secondary $\gamma^{\prime}$ ( $\sim 0 \mathrm{~nm}$ diameter), while both CG and SX exhibit a bimodal distribution of secondary $\gamma^{\prime}$ precipitates, with coarse cuboidal $\gamma^{\prime}$ particles having a $\sim 300 \mathrm{~nm}$ size and fine spherical $\gamma^{\prime}$ with an average diameter of about $35 \mathrm{~nm}$. 


\section{Mechanical testing}

Mechanical tests on FG and CG samples were performed on cylindrical specimens having a $13 \mathrm{~mm}$ gauge length, and a $4.3 \mathrm{~mm}$ diameter. SX samples, only tested in creep, have a $14 \mathrm{~mm}$ gauge length and a $4 \mathrm{~mm}$ diameter.

Before mechanical testing, samples were low-stress polished with $\mathrm{SiC}$ papers up to a 4000 grade for creep testing under air. For all the other mechanical tests, additional polishing with diamond sprays was performed up to a $1 \mu \mathrm{m}$ grade.

Pure creep tests in air were conducted with a conventional creep device in tension and in constant load mode. Elongation was continuously monitored using a Linear Variable Displacement Transducer (LVDT).

Creep tests in vacuum were performed with an Instron 1271 type hydraulic machine equipped with a vacuum chamber designed in the laboratory.

Tensile and dwell-fatigue tests were conducted in air at $700{ }^{\circ} \mathrm{C}$ with an Instron 8862 type electromechanical machine. They were performed under stress controlled mode with trapezoidal signals, with a stress ratio $R_{\sigma}=0.05$. Previous studies $[10-12,14]$ have shown that depending on the hold periods $(\Delta t)$ at maximum applied stress, the material durability is governed either by pure fatigue damage or pure creep damage. It was thus decided to cover a wide range of hold periods (from $1 \mathrm{~s}$ to $3600 \mathrm{~s}$ ). The maximum applied stresses, ranging from $750 \mathrm{MPa}$ to $1070 \mathrm{MPa}$ for the dwell-fatigue tests, have been chosen in order to cover possible industrial applications. Specimen elongation measurements were performed using a high temperature extensometer.

\section{Results}

\section{$\underline{\text { Creep behavior }}$}

The $\mathrm{AD} 730^{\mathrm{TM}}$ alloy was designed to withstand temperatures up to $750{ }^{\circ} \mathrm{C}$ [3-5]. It was therefore decided to conduct creep tests at $700{ }^{\circ} \mathrm{C}$ and $850^{\circ} \mathrm{C}$, in order to cover a wide range of temperatures.

First, FG and CG microstructures were tested at $700{ }^{\circ} \mathrm{C}$, between $600 \mathrm{MPa}$ and $950 \mathrm{MPa}$ (Figure 2.a.).

The results of these tests were surprising: indeed, FG and CG present very close creep properties, especially between $750 \mathrm{MPa}$ and $950 \mathrm{MPa}$. This indicates that the grain size is not a creep controlling parameter under these conditions.

At lower stresses $(\sigma<750 \mathrm{MPa}), \mathrm{CG}$ becomes more creep resistant than FG. A change of slope is then observed on a time to rupture/applied stress plot (Figure 2.b.), suggesting a change of creep deformation mechanisms occurring around $750 \mathrm{MPa}$, for both microstructures.

It has been demonstrated that the alloy's microstructure is stable enough to be used at higher temperatures (especially for CG microstructures) [15], hence creep tests were performed at $850^{\circ} \mathrm{C}$, on FG, CG and SX microstructures. Such temperature is very high for this kind of alloy, hence oxidation and microstructure overageing are supposed to have a strong impact on the creep properties [16]. A selection of creep curves is shown in Figure 3.
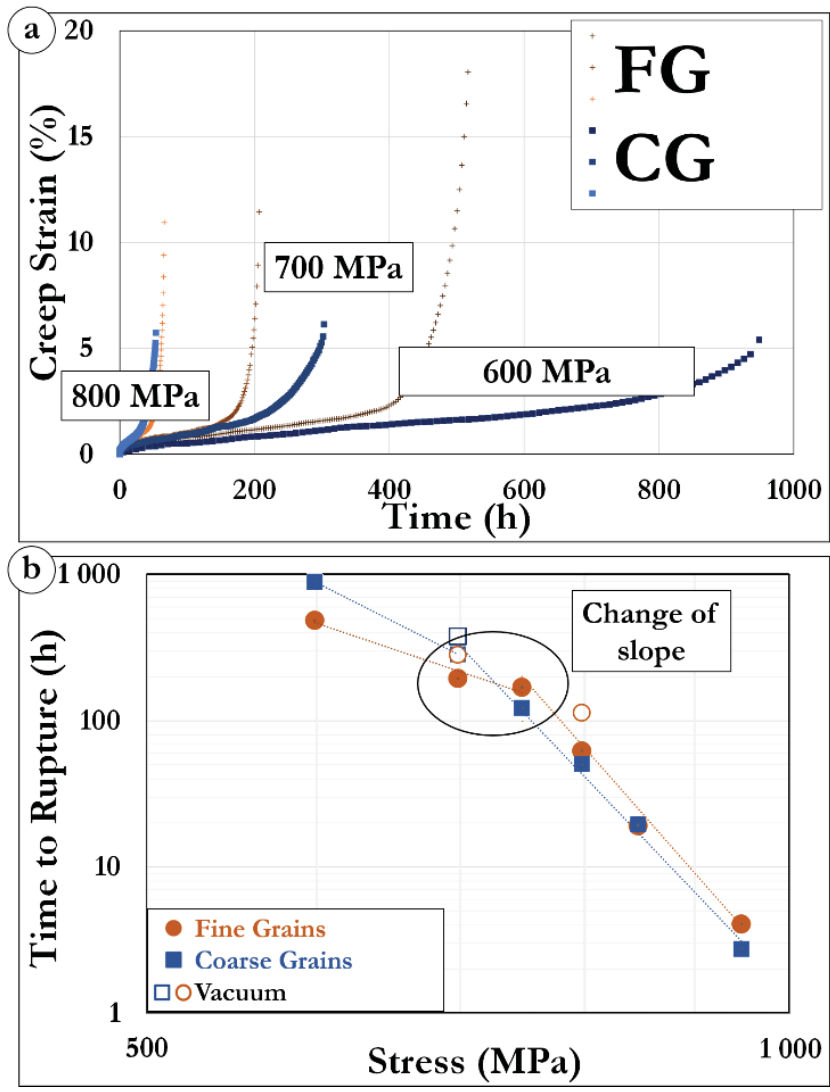

Figure 2. (a) Creep tests at $700{ }^{\circ} \mathrm{C}-\mathrm{CG}$ and $\mathrm{FG}$ microstructures; (b) Time to rupture as a function of the applied stress $-700^{\circ} \mathrm{C}$.

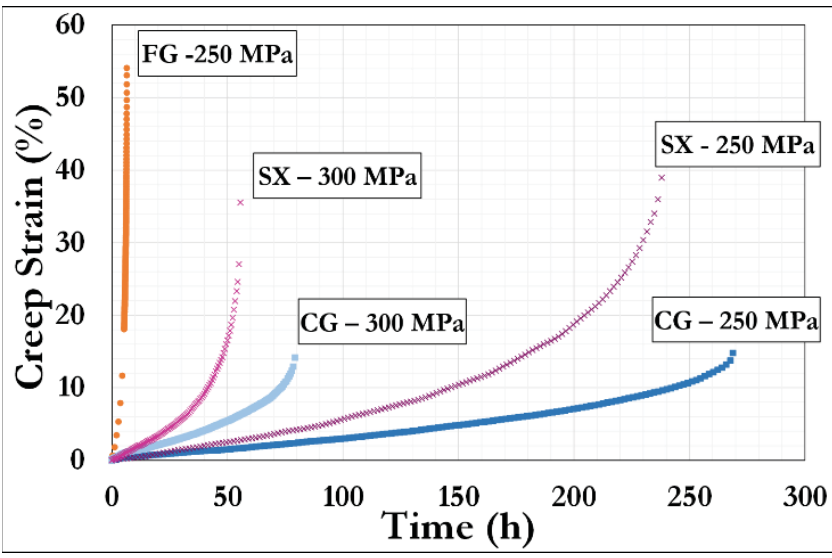

Figure 3. Creep curves at $850{ }^{\circ} \mathrm{C}$ - Comparison between all three microstructures.

The comparison between FG and CG confirms the predominant role of the grain size on creep properties at $850{ }^{\circ} \mathrm{C}$ : $\mathrm{CG}$ microstructure is, as expected [17], more creep resistant than FG, in terms of creep life, elongation and creep strain rate.

However, the results of the creep tests performed on SX samples (having the same $\gamma^{\prime}$ precipitation microstructure than CG microstructure (Figure 1)) were quite surprising: both microstructures present similar creep properties in these conditions, even with a time to failure slightly shorter for the SX samples. A significantly higher durability for the SX samples would have been expected in comparison to CG samples. 
These results suggest that the grain size is not the only parameter controlling the creep properties. Indeed, above a grain size threshold, the intragranular $\gamma^{\prime}$ volume fraction becomes the main creep controlling parameter, according to Reed [17].

\section{$\underline{\text { Strain rate and oxidation effects }}$}

Fatigue and dwell-fatigue tests have been performed at $700{ }^{\circ} \mathrm{C}$ for both the FG and CG microstructures. The average strain rate for the testing conditions was close to $\dot{\varepsilon}=5 \cdot 10^{-3} \mathrm{~s}^{-1}$. In order to analyze the results, it was necessary to characterize the monotonic tensile properties at $700{ }^{\circ} \mathrm{C}$ of both microstructures for similar strain rates. Tensile tests have been conducted for this purpose. To evaluate the strain rate sensitivity of this alloy at $700{ }^{\circ} \mathrm{C}$, monotonic tensile tests have also been performed for two other strain rates $\left(\dot{\varepsilon}=10^{-4} \mathrm{~s}^{-1}\right.$ and $\dot{\varepsilon}=10^{-5} \mathrm{~s}^{-1}$ ), for both FG and CG microstructures.
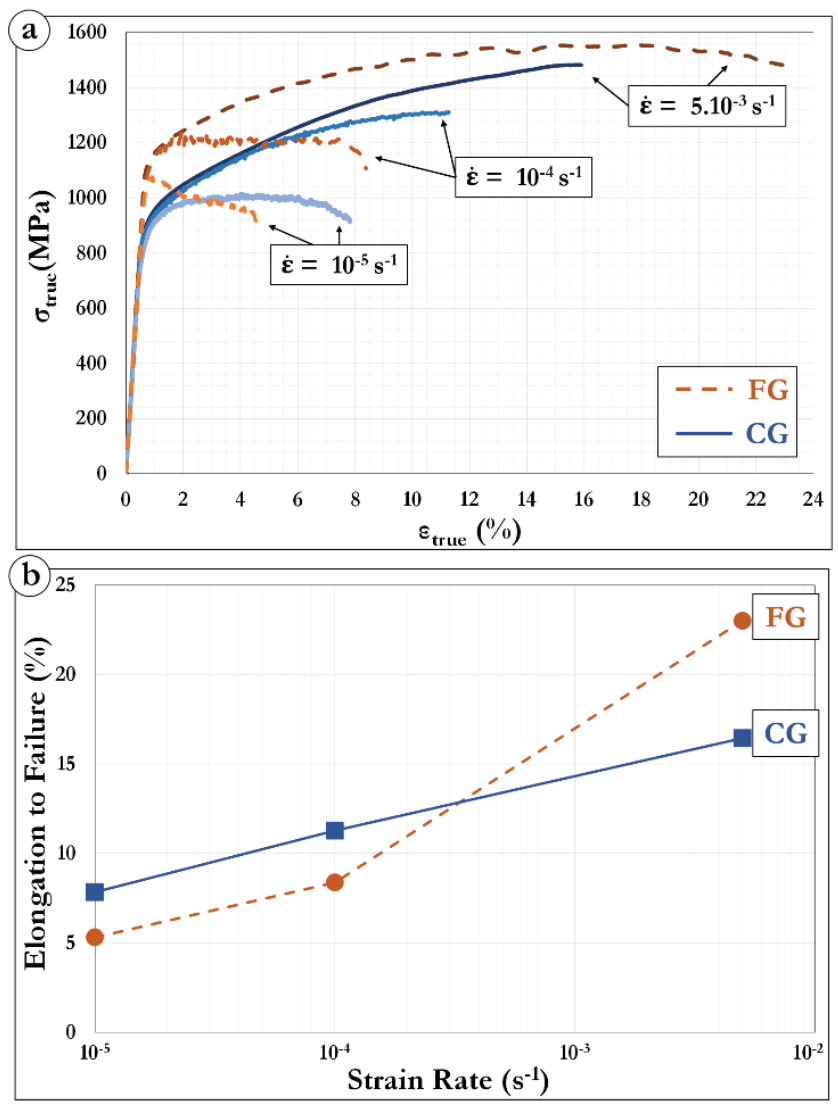

Figure 4. Tensile curves at different strain rates at $700{ }^{\circ} \mathrm{C}$ (a) and corresponding plastic strain at failure (b).

Figure 4 presents the results of these tensile tests. Tensile properties corresponding to these tests are summarized in Table III hereafter.

In accordance with a Hall-Petch approach [18], FG microstructure shows higher tensile properties (Yield Strength) than CG for each strain rate. However, for both FG and $C G$ microstructures, the strain rate effect on the yield strength remains very low (the YS decreases by less than $10 \%$ as the strain rate decreases by two decades). A noticeable influence of the strain rate on the high temperature ductility was however noticed: the elongation is at least twice higher for the quickest test $\left(\dot{\varepsilon}=5.10^{-3} \mathrm{~s}^{-1}\right)$ compared to the slowest $\left(\dot{\varepsilon}=10^{-5} \mathrm{~s}^{-1}\right)$, for both microstructures.

Table III. Tensile properties at $700^{\circ} \mathrm{C}$.

\begin{tabular}{lccccc}
\hline Microstructure & $\begin{array}{c}\text { Strain } \\
\text { Rate } \\
\left(\mathbf{s}^{-1}\right)\end{array}$ & $\begin{array}{c}\mathbf{E} \\
(\mathbf{G P a})\end{array}$ & $\begin{array}{c}\text { UTS } \\
(\mathbf{M P a})\end{array}$ & $\begin{array}{c}\text { Yield } \\
\text { Strength } \\
(\mathbf{M P a})\end{array}$ & $\begin{array}{c}\boldsymbol{\varepsilon} \% \\
(\text { Failure })\end{array}$ \\
\hline \multirow{3}{*}{ Fine Grain } & $5.10^{-3}$ & 169 & 1554 & 1123 & 23 \\
& $10^{-4}$ & 158 & 1234 & 1104 & 8 \\
& $10^{-5}$ & 168 & 1132 & 1102 & 5 \\
\hline \multirow{3}{*}{ Coarse Grain } & $5.10^{-3}$ & 168 & 1483 & 886 & 16 \\
& $10^{-4}$ & 166 & 1313 & 863 & 11 \\
& $10^{-5}$ & 158 & 1018 & 823 & 8 \\
\hline
\end{tabular}

This is due to a strong influence of oxidation on this material at this temperature: when the strain rate is low, oxidation has enough time to develop and to assist intergranular cracking, limiting the deformation at failure. In addition, when the strain rate is high $\left(5.10^{-3} \mathrm{~s}^{-1}\right)$, the elongation is greater for FG microstructure than $\mathrm{CG}$, while it is the opposite when the strain rate is decreased $\left(10^{-4}\right.$ and $\left.10^{-5} \mathrm{~s}^{-1}\right)$. These results are consistent with the well-known effects of intergranular oxidation: CG microstructure having less grain boundaries, is less sensitive to grain boundary oxidation than FG microstructure [19-22].

It is therefore necessary to evaluate the influence of oxidation on other mechanical properties. Additional creep tests were then conducted under vacuum, at $700{ }^{\circ} \mathrm{C}$, but also at $850{ }^{\circ} \mathrm{C}$ where oxidation should have a stronger impact. These tests were made on both FG and CG microstructures.

On Figure 5, it is observed that for both microstructures, and both temperatures, the tests performed under vacuum lead systematically to a longer time to rupture compared to the test performed in air (about 1.5 times longer).
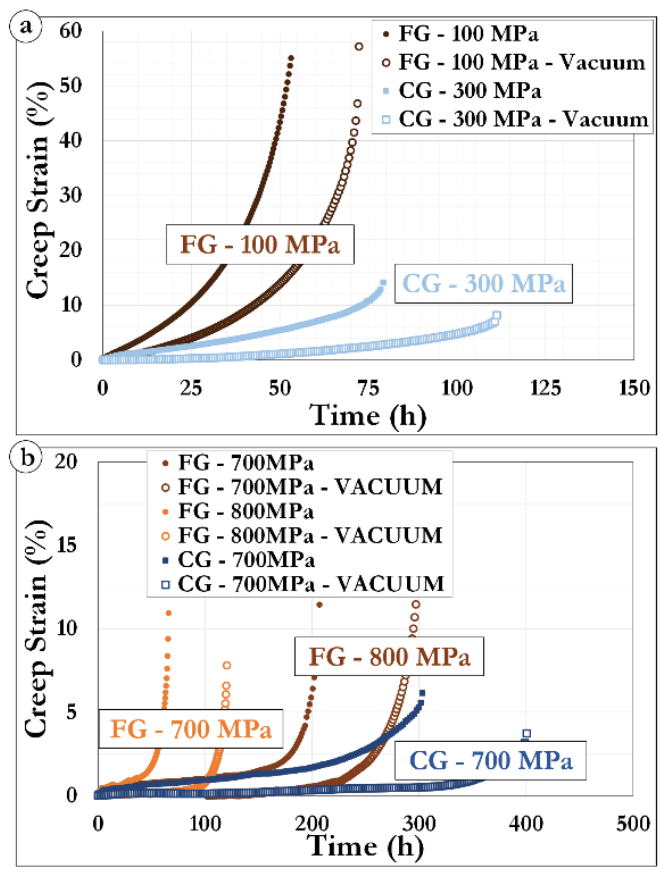

Figure 5. Comparison between creep tests performed under air and vacuum at (a) $850{ }^{\circ} \mathrm{C}$; (b) $700{ }^{\circ} \mathrm{C}$. 

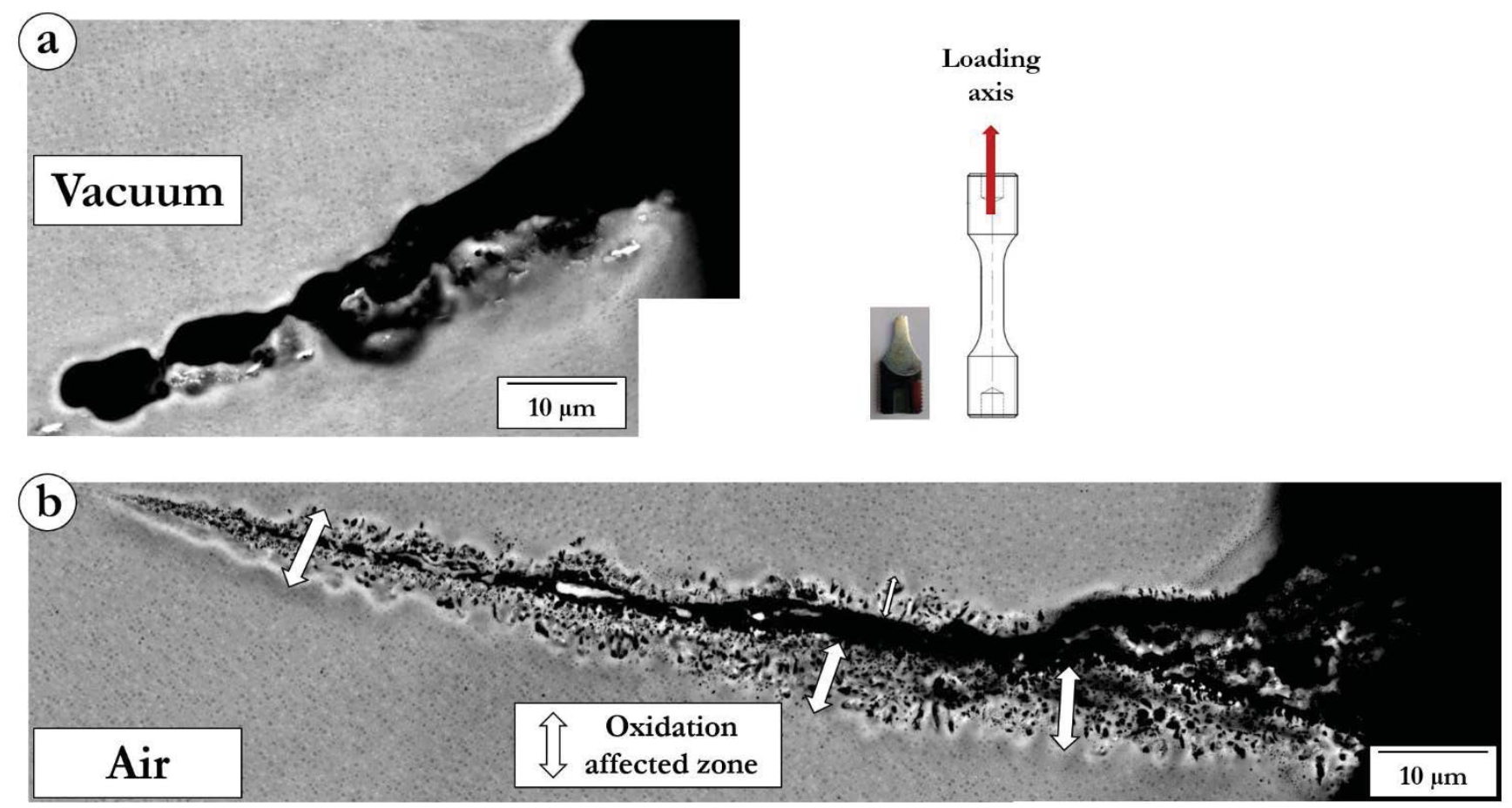

Figure 6. SEM examination of longitudinal cut from $\mathrm{CG}$ crept specimen $\left(850^{\circ} \mathrm{C} / 300 \mathrm{MPa}\right)$ in back scattered electron mode - (a) Vacuum ( $1 \mathrm{~mm}$ from the fracture surface); (b) Air ( $5 \mathrm{~mm}$ from the fracture surface)

SEM observations along longitudinal sections of crept specimens (creep in vacuum compared to creep in air) reveals the oxidation effects at grain boundaries (Figure 6): it is observed on these images that the oxidation affected zone can reach a few $\mu \mathrm{m}$ of thickness inside the secondary crack, and is assisting the crack's development (these secondary cracks are more than $110 \mu \mathrm{m}$ long in air/less than $65 \mu \mathrm{m}$ long in vacuum).

\section{$\underline{\text { Dwell-fatigue behavior }}$}

Rotating parts of turbine disks are submitted to complex mechanical loading, including cyclic and constant stress loadings. Thus, dwell-fatigue tests were conducted in order to be more representative of in-service loading. Both $\mathrm{CG}$ and FG microstructures were tested, at $700{ }^{\circ} \mathrm{C}$, under maximum applied stresses ranging from $750 \mathrm{MPa}$ to $950 \mathrm{MPa}$.

Previous studies on dwell-fatigue have demonstrated that when increasing the hold time, a transition occurs between "pure fatigue" and "pure creep" processes $[9,11-13,23]$. This transition can be determined either by looking at the strain-time curves, or by investigating the fracture surfaces of tested specimens. Figure 7 shows that, for a given maximum applied stress, the material's response is completely different depending on the hold time at maximum stress. For hold periods equal to $3 \mathrm{~s}$ or smaller, the cyclic behavior is close to a "pure fatigue", with a very limited cycling ratcheting for more than $90 \%$ of the test duration and with a rapid increase of the apparent plastic strain amplitude at the end of the test, corresponding to the development of the main fatal crack. For higher dwell times, the curves are closer to pure creep curves, where the three conventional creep stages (primary, secondary and tertiary) can be identified.

The surprising fact on Figure 7 is the cumulated time to failure reached for the longest dwell times ( $300 \mathrm{~s}$ and $3600 \mathrm{~s}$ ), that is much greater than the time to failure under pure creep condition.

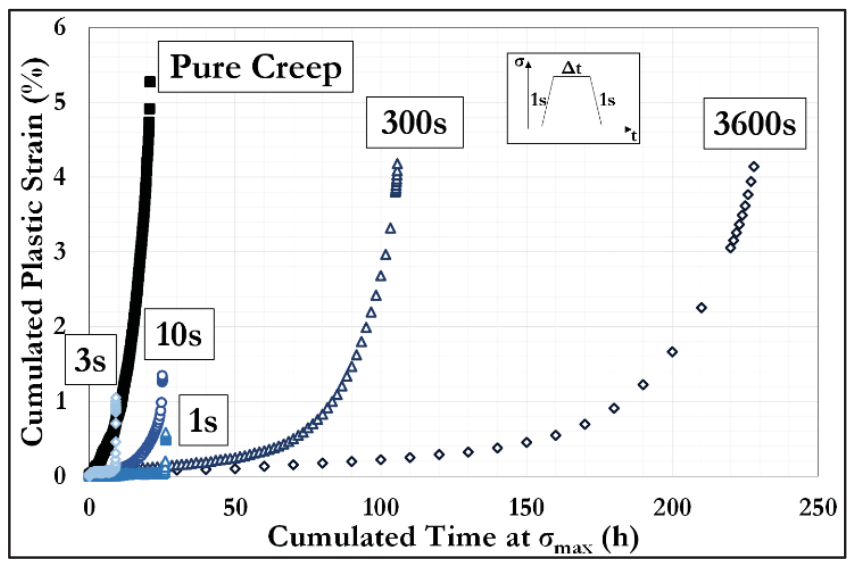

Figure 7. Dwell-Fatigue curves - Coarse Grain microstructure - $\mathrm{T}$ $=700{ }^{\circ} \mathrm{C} ; \sigma_{\max }=850 \mathrm{MPa} ; \mathrm{R}_{\sigma}=0.05$.

For sake of comparison, the curves obtained for both microstructures at a lower stress amplitude of $750 \mathrm{MPa}$ are plotted in Figure 8.a. for an intermediate value of dwell period $(\Delta t=10 \mathrm{~s})$ and in Figure 8.b. for a long dwell period $(\Delta t=300 \mathrm{~s})$.

It appears that, for long dwell times $(\Delta t \geq 10 \mathrm{~s})$, the behavior of both microstructures is changing when the maximum applied stress increases: in both cases $(\Delta \mathrm{t}=10 \mathrm{~s}$ and $\Delta \mathrm{t}=300 \mathrm{~s})$, the cumulated time at maximum stress is lower for the dwell-fatigue tests than for the pure creep tests when $\sigma_{\max }=750 \mathrm{MPa}$, but it is greater when $\sigma_{\max }=850 \mathrm{MPa}$. This suggests that a change of deformation mechanisms is occurring depending on the applied stress. With these changes, the loading/unloading phases may not have the same influence on the material's behavior under dwell-fatigue solicitations. 

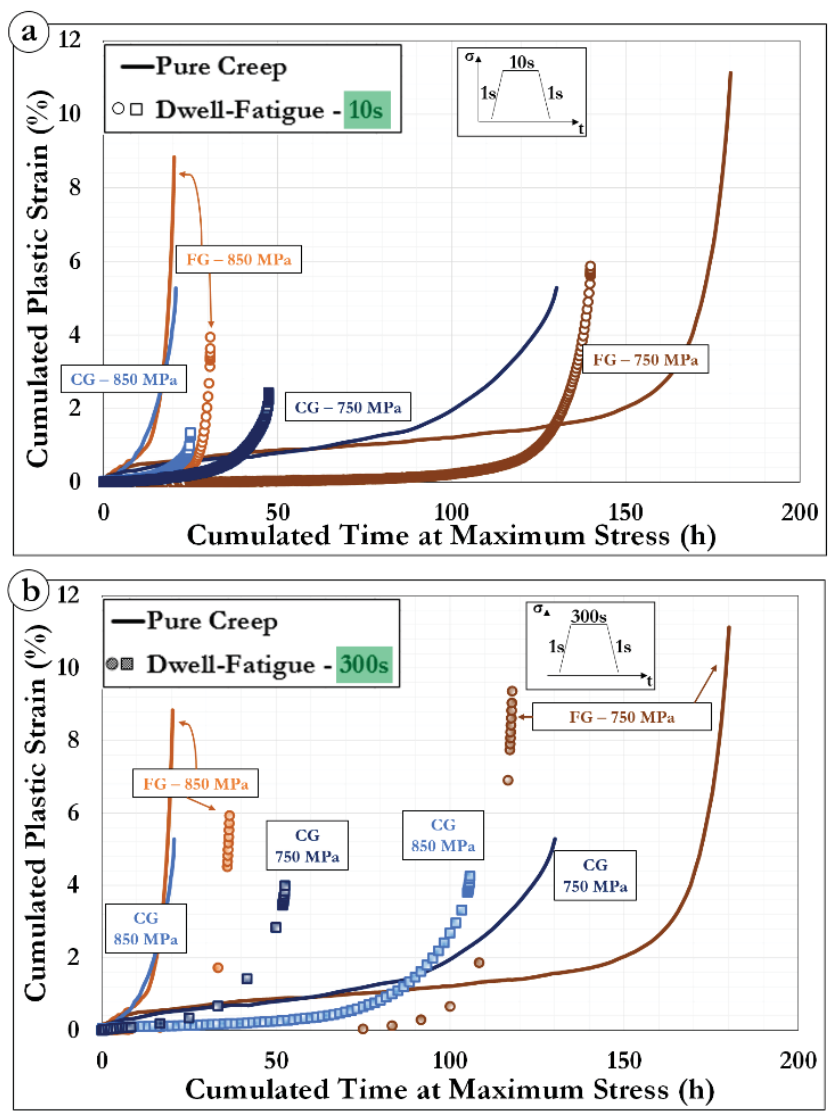

Figure 8. Pure creep tests compared to its counterpart in dwellfatigue $\Delta \mathrm{t}=10 \mathrm{~s}$ (a) and $\Delta \mathrm{t}=300 \mathrm{~s}(\mathrm{~b})$ for both FG and CG microstructures.

\section{Discussion}

\section{$\underline{\text { Creep }}$}

One way to analyze the creep controlling deformation mechanism in a range of temperature and loading conditions is to plot the minimum creep strain rate as a function of the applied stress [24] (Figure 9), and to look at the Norton's coefficients "n" (these coefficients are deduced from the Norton's law reported in Equation (1) below).

$$
\dot{\varepsilon}_{\min }=\alpha\left(\frac{\sigma}{\lambda}\right)^{n}
$$

The low values of the Norton's coefficients from the tests performed at $850{ }^{\circ} \mathrm{C}$ indicate that the creep deformation mechanisms of FG microstructure are mainly diffusion controlled $(\mathrm{n} \sim 1)$, while CG and SX microstructures creep behaviors are both partly controlled by dislocation creep $(\mathrm{n} \sim 5)$. These results are to be linked to the intragranular $\gamma^{\prime}$ volume fraction: CG and SX have a greater $\gamma^{\prime}$ volume fraction $(\sim 32 \%)$ than FG microstructures $(\sim 25 \%)$ (Table II), which explains the enhanced role of dislocations in controlling the creep deformation in CG and SX specimens.

The analysis of the crept specimens, especially the detailed SEM observations of cuts performed along the tensile direction, revealed that FG specimens develop preferential damage in the form of pores along the grain boundaries/primary $\gamma^{\prime}$ interfaces (Figure 10.a.), where vacancies diffusion occurred during the test. Damage is localized at grain boundaries for CG microstructure (Figure 10.b.).

This points out that the diffusion mechanisms here could be vacancies diffusion along grain boundaries, inducing grain boundary sliding (Lifshitz sliding $[25,26])$. Hence, at this high temperature, the better creep properties directly result from the decrease in grain boundary density.

However, it has been seen that SX and CG exhibit similar creep deformation mechanisms, both linked to dislocations motion in the matrix. Thus, when a grain size threshold is reached (and hence, when the intragranular $\gamma^{\prime}$ volume fraction is higher), the grain size is no longer the main creep controlling deformation parameter. The intragranular $\gamma^{\prime}$ volume fraction is the most important parameter in that case.

On the other hand, at $700{ }^{\circ} \mathrm{C}$ and above $750 \mathrm{MPa}$, it appears that the grain size is no longer a creep controlling parameter: above this applied stress, CG and FG microstructure show similar creep behaviors, with very similar Norton's coefficients (22 and 17 respectively). These high values indicate that the creep deformation mechanisms are dislocation type for both microstructures. Another parameter is then controlling the creep deformation mechanisms. Some studies already analyzed this phenomena, suggesting that the creep-controlling parameter in this range of temperatures and for this kind of alloys may be the secondary $\gamma^{\prime}$ size and distribution $[12,14,27-29]$. In this study, the secondary $\gamma^{\prime}$ size is almost the same for both microstructures ( $40 \mathrm{~nm}$ for FG microstructures, $35 \mathrm{~nm}$ for the CG one), but with a slightly different secondary $\gamma^{\prime}$ volume fraction (presence of primary $\gamma^{\prime}$ in the FG, cuboidal secondary $\gamma^{\prime}$ in the CG). Both these parameters (secondary $\gamma^{\prime}$ size, and volume fraction) may then be creep-controlling parameters under these creep conditions.

At lower applied stresses (between $600 \mathrm{MPa}$ and $750 \mathrm{MPa}$ ), the behavior of those microstructures differ. It becomes fully diffusion type for $\mathrm{FG}(\mathrm{n} \sim 2)$ and a mix dislocation/diffusion for $\mathrm{CG}$ microstructure $(\mathrm{n} \sim 5)$. Hence, a threshold stress is evidenced, above which the creep deformation mechanisms for both microstructures are changing. The presence of such a threshold stress has already been observed in previous studies [30-33]. These results suggest that the creep deformation mechanisms at higher stresses are governed by a regime where the dislocations shear the $\gamma^{\prime}$ precipitates, whereas dislocation climb and particles by-passing mechanism are often the rate limiting deformation mechanisms below this threshold stress.

Post-mortem observations along longitudinal cuts of crept specimens at $700{ }^{\circ} \mathrm{C}$, both with an applied stress higher than the threshold stress $750 \mathrm{MPa}$, and an applied stress lower than it, show a strong dislocation activity through $\gamma^{\prime}$ precipitates shearing (Figure 11) in both cases. Moreover, regardless of the applied stress (meaning of the time spent in temperature), the $\gamma^{\prime}$ size is not affected by creep tests at this temperature.

Figure 12 displays the evolution of the creep strain rates of some tests conducted at $700^{\circ} \mathrm{C}$, on $\mathrm{FG}$ and $\mathrm{CG}$ microstructures. It can be seen that, for both microstructures, the creep strain rate is initially decreasing rapidly, up to a minimum, and then increasing progressively. No secondary stage is observed, for most applied stresses, except at $600 \mathrm{MPa}$. The curves from the tests conducted with an applied stress of $600 \mathrm{MPa}$ exhibit a small plateau at minimum creep strain rate, evidencing a short secondary stage. 


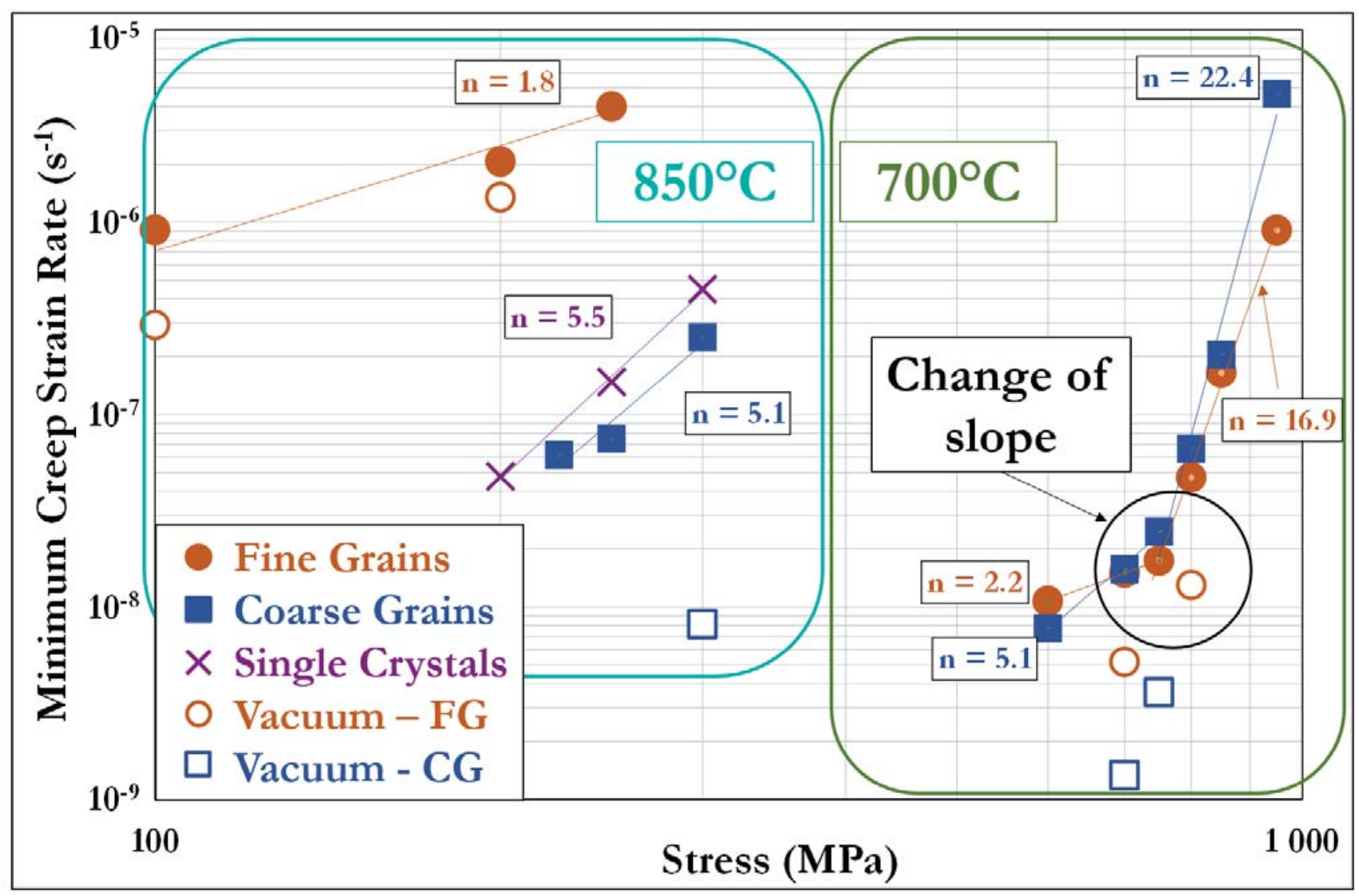

Figure 9. Minimum creep strain rate as a function of the applied stress; $\mathrm{n}=$ Norton's coefficient.

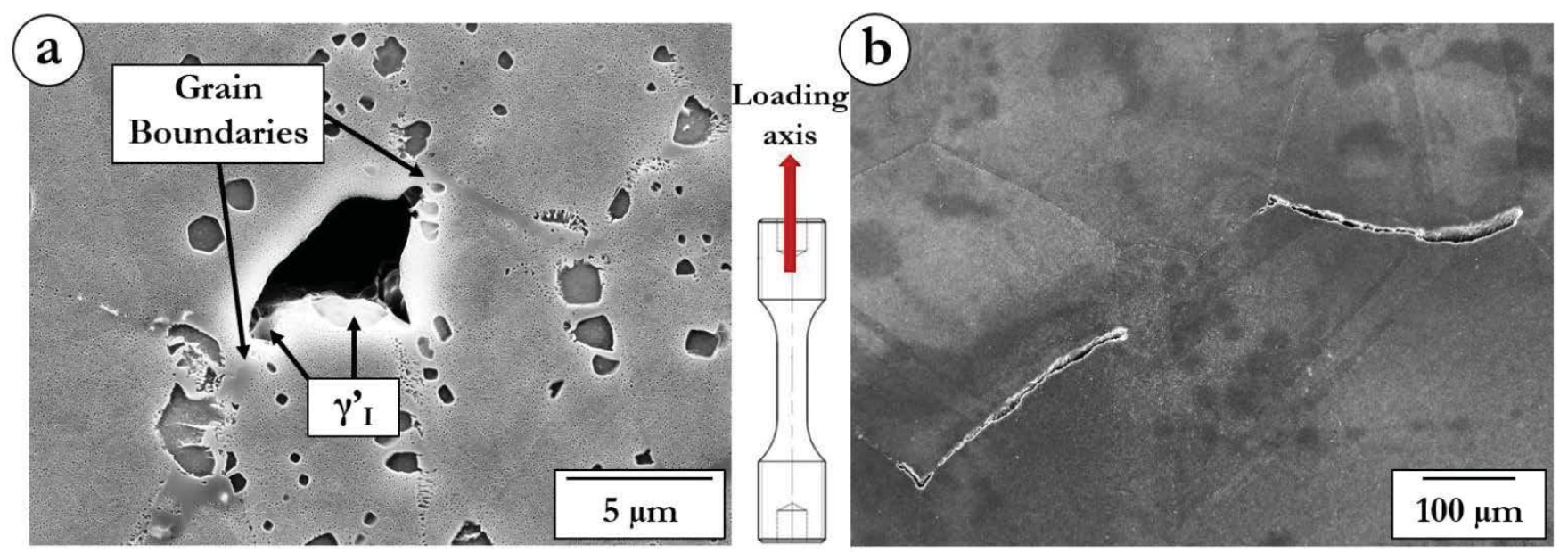

Figure 10. Post-mortem longitudinal observations; Creep $850{ }^{\circ} \mathrm{C} / 250 \mathrm{MPa}$ : (a) Fine Grain microstructure; (b) Coarse Grain microstructure.

When the applied stress decreases, this minimum strain rate (which represents the transition between the secondary and tertiary creep stage, hence between the creep behavior and creep damage) is reached at a greater elongation. This suggests either changes in the creep deformation mechanisms, or an influence of the environment on the creep properties. More likely, both these phenomena may be interacting simultaneously.

Further TEM observations would be necessary to confirm the differences in deformation mechanisms below and above this threshold stress.
Moreover, additional experiments under vacuum are currently under progress to check if the minimum strain rate dependence to the applied stress observed under air at $700{ }^{\circ} \mathrm{C}$ is also sensitive to the environment, as one would expect based on the first results obtained under vacuum shown in Figure 9. 


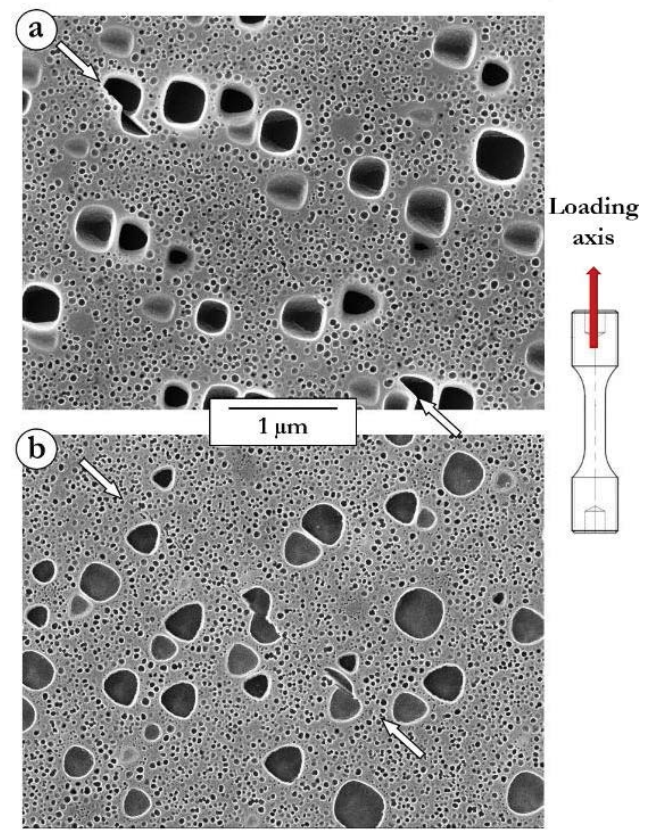

Figure 11. Post-mortem observations on longitudinal cut from crept specimens at $700{ }^{\circ} \mathrm{C}$, Coarse Grain microstructure; (a) $700{ }^{\circ} \mathrm{C} / 600 \mathrm{MPa}$; (b) $700{ }^{\circ} \mathrm{C} / 850 \mathrm{MPa}$. Arrows indicate shearing mechanisms.
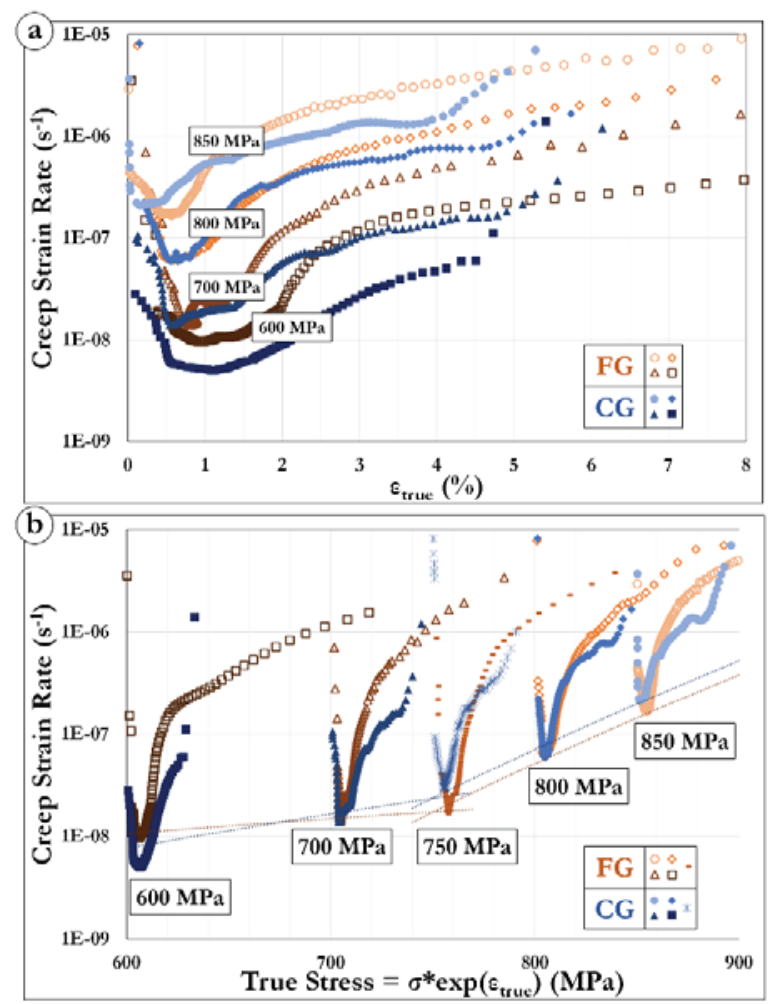

Figure 12. Evolution of the creep strain rate as a function of: (a) the creep strain; (b) the true stress.

\section{Dwell-Fatigue}

The dependence of the viscoplastic properties to the hold time has already been studied in previous works [9,11-13]. In our study, it appears that the transition between pure creep type and pure fatigue occurs around a hold period of $10 \mathrm{~s}$. This paper will not discuss this issue further.

However, our study will focus on the dependence of the accumulated time at maximum applied stress to the maximum applied stresses, for long hold periods (longer than $10 \mathrm{~s}$ ). It has been shown earlier that, depending on the maximum applied stress, the loading/unloading phases might have a beneficial or detrimental influence on the cumulated time at maximum applied stress (Figure 8). A stress threshold has then been evidenced, above which the loading/unloading phases during a dwell-fatigue test become beneficial.

One way to understand the changes above and under this threshold stress is to observe tested samples. No difference between the samples, whether they have been tested with a maximum applied stress higher or lower than this threshold stress, have been found when looking at the fracture surfaces [13]. Observations of longitudinal cuts from the same tested samples have been performed (Figure 13). Both samples exhibit intense dislocations activity with very long shearing bands, like the ones observed on crept samples. But again, no change in deformation mechanisms could be detected between those specimens thanks to SEM observations.

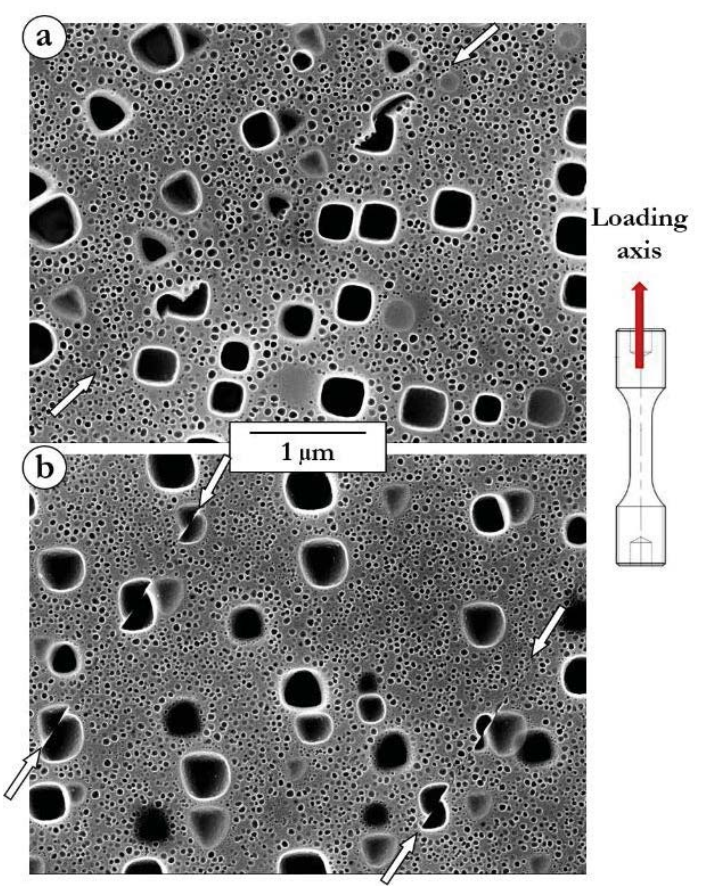

Figure 13. Post-mortem observations on longitudinal cut from tested specimens in dwell-fatigue; at $700{ }^{\circ} \mathrm{C} ; \Delta \mathrm{t}=10 \mathrm{~s}$; Coarse Grain microstruscture; (a) $\sigma_{\max }=750 \mathrm{MPa}$; (b) $\sigma_{\max }=850 \mathrm{MPa}$. Arrows indicate shearing mechanisms.

One interrupted test has been conducted using the FG microstructure, under the following conditions: $700{ }^{\circ} \mathrm{C}$, $\sigma_{\max }=850 \mathrm{MPa}, \mathrm{R}_{\sigma}=0.05$ and $\Delta \mathrm{t}=300 \mathrm{~s}$. Under these conditions, it was previously shown that the loading/unloading phases are beneficial to the time to failure compared to creep (cumulated time at maximum applied stress in dwell-fatigue is $37 \mathrm{~h}$ vs $20 \mathrm{~h}$ in pure creep).

Hysteresis loops of some selected cycles $(\mathrm{N}=40,110,170,210$ and 235) have been plotted (Figure 14). It can be seen that for Cycle 40 , the unloading phase is completely elastic (the curve is completely superimposed with the red straight line), whereas a 
small "negative plastic deformation" is noticed on Cycles 110, 170, 210 and 235 (the unloading phases for these Cycles 110, 170, 210 and 235 are no longer completely superimposed with the red straight line). Moreover, the critical stress $\sigma_{c}$ at which this phenomena is occurring (highlighted in Figure 14.b. by red crosses) increases progressively during the test, up to a plateau around $\sigma_{\mathrm{c}}=450 \mathrm{MPa}$. Due to these "negative" plastic offsets, occurring at each cycles during the test, the overall plastic strain rate is slowed down.
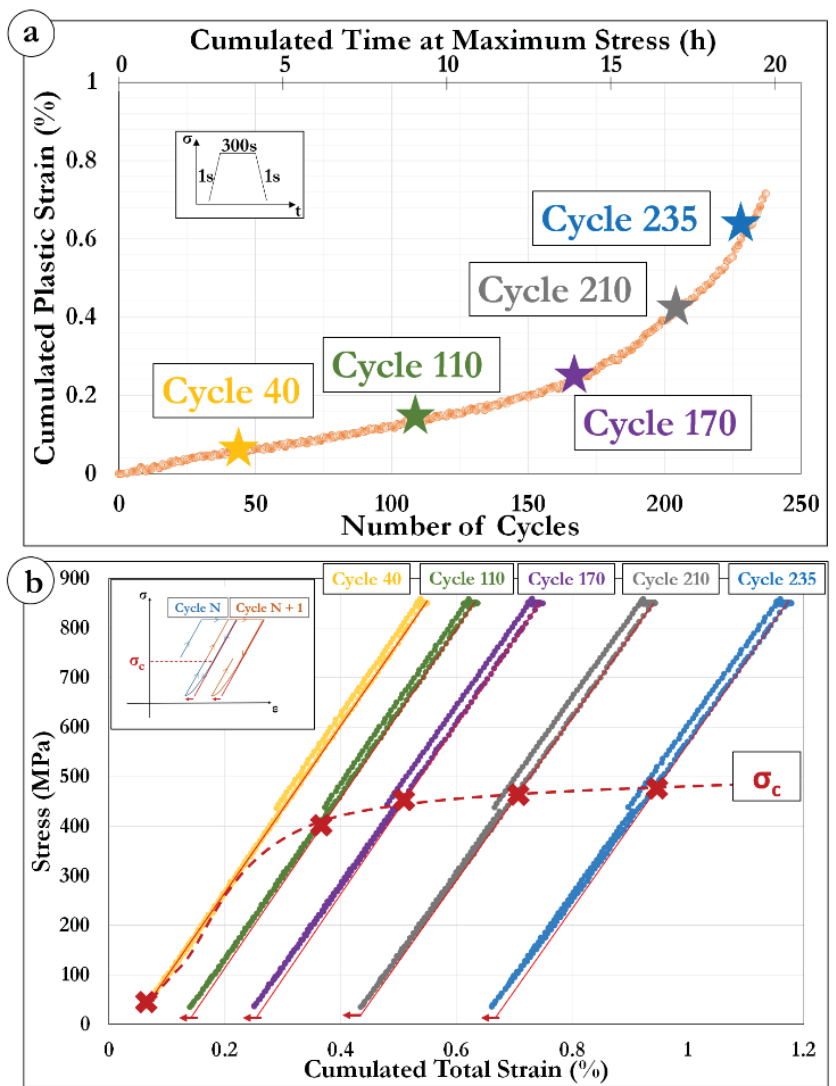

Figure 14. Dwell-Fatigue curves from an interrupted test; Fine Grain microstructure; $700{ }^{\circ} \mathrm{C}-\sigma_{\max }=850 \mathrm{MPa}, \Delta \mathrm{t}=300 \mathrm{~s}$,

$\mathrm{R}_{\sigma}=0.05$; (a) Cumulated plastic strain evolution; (b) Hysteresis loops of several cycles during the test.

This phenomena might be explained either by the recovery processes occurring during the unloading phases or by a pronounced Bauschinger effect. If a dwell-fatigue test, for a given hold period, is analyzed as a pure creep test with periodic unloading phases, the recovery processes may be linked to the creep deformation mechanisms occurring during the hold periods. In that case, at high applied stress $\left(\sigma_{\max }=850 \mathrm{MPa}\right.$, giving a ratio maximum applied stress $/ 0.2 \%$ yield stress $\sim 0.76$ ), the creep deformation mechanisms are dislocations type. There, the recovery processes during unloading are beneficial to the overall material's behavior. At lower maximum stresses (i.e. lower maximum applied stress $/ 0.2 \%$ yield stress ratio), the creep deformation mechanisms are a mix between dislocation type and diffusion. In this case, the recovery processes are no longer beneficial. The loading/unloading phases are then simply seen as an elastic cycling component contributing to fatigue damage, deleterious to the material's lifetime compared to pure creep. Moreover, it can also be deduced that the maximum applied stress is too low to induce a shift of the yield surface center at a high enough stress value leading to a negative plastic offset during unloading.

Closer TEM observations of specimens issued from interrupted tests are needed to confirm and to get a better understanding of this. More interrupted tests are therefore planned, on both microstructures, and at different maximum applied stresses.

\section{Conclusions}

The aim of this study was to evaluate the mechanical behavior and durability of the $\mathrm{AD} 730^{\mathrm{TM}}$ material in a context of high temperatures $\left(700^{\circ} \mathrm{C}-850^{\circ} \mathrm{C}\right)$ for which the viscoplasticity plays an important role. Hence, creep and dwell-fatigue tests were conducted on three microstructures, having different $\gamma^{\prime}$ size and distribution, and different grain sizes.

It appears that, as expected, the grain size is a main creepcontrolling parameter at $850{ }^{\circ} \mathrm{C}$, along with the intragranular $\gamma^{\prime}$ volume fraction. At $700{ }^{\circ} \mathrm{C}$, the creep-controlling parameters are dependent on the applied stress, for both $\mathrm{CG}$ and $\mathrm{FG}$ microstructures. This dependence is assumed to be linked to a change in operative dislocations micromechanisms.

Oxidation has been shown to have a detrimental influence on the alloy's mechanical properties especially for FG microstructure in which a pronounced decrease of tensile ductility has been observed for slow strain rate tests. Moreover, the creep life is longer under vacuum, whatever the microstructure and testing temperature.

The dwell-fatigue durability strongly depends on the hold time at maximum applied stress for both CG and FG microstructures. At low maximum applied stress and short hold times, the dwell-fatigue lifetime is bounded by the creep life while at high applied stress and long dwell times, the unloading phases are beneficial to the time to failure. This change results from the presence or not of a negative plastic offset during unloading phases, indicating complex Bauschinger effects.

\section{Acknowledgments}

The authors would like to thank Aubert \& Duval for providing the materials, for L.T. PhD grant and for their continuous interest in this study. SAFRAN SA is gratefully acknowledged for financial support, and for the continuous collaboration for over 10 years with Institut Pprime on Ni-based superalloys activities.

\section{References}

1. J.W. Brooks, P.J. Bridges, "Metallurgical Stability of Inconel 718," Superalloys 1988, (TMS: Warrendale, PA, USA, 1988), 33-42.

2. A. Devaux, L. Nazé, R. Molins, et al., "Gamma double prime precipitation kinetic in Alloy 718," Mater. Sci. Eng. A, 486 (1-2) (2008) 117-122.

3. A. Devaux, E. Georges, P. Héritier, "Properties of New C\&W Superalloys for High Temperature Disk Applications," 7th International Symposium on Superalloy 718 and Derivatives, Eds. E.A. Ott, J.R. Groh, et al., (TMS: Warrendale, PA, USA, 2010), 223-235.

4. A. Devaux, E. Georges, P. Héritier, "Development of New C\&W Superalloys for High Temperature Disk Applications," Adv. Mater. Res., 278 (2011) 405-410.

5. A. Devaux, B. Picqué, M. Gervais, et al., "AD730"TM - A New 
Nickel-Based Superalloy for High Temperature Engine Rotative Parts," Superalloys 2012, Eds. E. Huron, R. Reed, et al., (TMS: Warrendale, PA, USA, 2012), 911-919.

6. A. Devaux, A. Helstroffer, J. Cormier, et al., "Effect of Aging Heat-Treatment on Mechanical Properties of AD730 $0^{\mathrm{TM}}$ Superalloy," 8th International Symposium on Superalloy 718 and Derivatives, Eds. E. Ott, A. Banik, et al., (TMS: Warrendale, PA, USA, 2014), 521-535.

7. G.L. Chen, L.G. Fritzemeier, X. Xie, et al., "Induced creep and creep/fatigue of a nickel-base superalloy at ambient temperatures," Metall. Trans. A, 13 (11) (1982) 1951-1955.

8. R. Miner, J. Gayda, R. Maier, "Fatigue and creep-fatigue deformation of several nickel-base superalloys at $650{ }^{\circ} \mathrm{C}$," Metall. Trans. A, 13 (October) (1982) 1755-1765.

9. J. Zrník, J. Semeňák, V. Vrchovinský, et al., "Influence of hold period on creep - fatigue deformation behaviour of nickel base superalloy," Mater. Sci. Eng. A, 319 (321) (2001) 637-642.

10. B. Flageolet, "Effet du vieillissement du superalliage base nickel N18 pour disques de turbines sur sa durabilité en fatigue et en fatigue-fluage à $700^{\circ} \mathrm{C} "$, (Ph.D. thesis, ENSMA, France, 2005).

11. T. Billot, "Comportement et endommagement en fatigue et fatigue-fluage à haute température de différents états microstructuraux du superalliage base-nickel Udimet 720", (Ph.D. thesis, ENSMA, France, 2010).

12. T. Billot, P. Villechaise, M. Jouiad, et al., "Creep-fatigue behavior at high temperature of a UDIMET 720 nickel-base superalloy," Int. J. Fatigue, 32 (5) (2010) 824-829.

13. L. Thébaud, P. Villechaise, J. Cormier, et al., "Relationships between Microstructural Parameters and Time-Dependent Mechanical Properties of a New Nickel-Based Superalloy AD730"TM," Metals, 5 (4) (2015) 2236-2251.

14. A. Laurence, "Impact du sur-vieillissement métallurgique sur le comportement et la durabilité du superalliage base nickel René 65", (Ph.D. thesis, ENSMA, France, 2016).

15. A. Devaux, L. Berglin, L. Thebaud, et al., "Mechanical properties and development of supersolvus heat treated new nickel base superalloy AD730TM," MATEC Web of Conferences, (EDP Sciences, 2014), 01004.

16. E. Chateau, L. Rémy, "Oxidation-assisted creep damage in a wrought nickel-based superalloy: Experiments and modelling," Mater. Sci. Eng. A, 527 (7-8) (2010) 1655-1664.

17. R.C. Reed, The Superalloys: Fundamentals and Applications (Cambridge University Press, 2006).

18. E.O. Hall, Yield point phenomena in metals and alloys (Springer Science \& Business Media, 1970).

19. C.J. McMahon, L.F. Coffin, "Mechanisms of Damage and Fracture in of a Cast Nickel-Based Superalloy," Metall. Trans., 1 (December) (1970) 3443-3450.

20. C.J. McMahon, "On the mechanism of premature in-service failure nickel-base superalloy gas turbine blades," Mater. Sci. Eng., 13 (3) (1974) 295-297.
21. E. Andrieu, R. Molins, H. Ghonem, et al., "Intergranular crack tip oxidation mechanism in a nickel-based superalloy," Mater. Sci. Eng. A, 154 (1) (1992) 21-28.

22. T.P. Gabb, J. Telesman, A. Banik, et al., "Use of slow strain rate tensile testing to assess the ability of several superalloys to resist environmentally assisted intergranular cracking," 8th International Symposium on Superalloy 718 and Derivatives, Eds. E. Ott, A. Banik, et al., (TMS: Warrendale, PA, USA, 2014), 639-654.

23. P. Villechaise, J. Cormier, T. Billot, et al., "Mechanical Behavior and Damage Processes of Udimet 720Li: Influence Of Localized Plasticity At Grain Boundaries," Superalloys 2012, (TMS: Warrendale, PA, USA, 2012), 15-24.

24. F. Nabarro, H. de Villiers, The Physics of Creep (Taylor \& Francis, London, 1995).

25. I.M. Lifshitz, "On The Theory Of Diffusion-Viscous Flow Of Polycrystalline Bodies," Sov. Phys. Jetp, 17 (4) (1963) 909920.

26. T.G. Langdon, "Grain boundary sliding revisited: Developments in sliding over four decades," J. Mater. Sci., 41 (3) (2006) 597-609.

27. A. Laurence, J. Cormier, P. Villechaise, et al., "Impact of the solution cooling rate and of thermal aging on the creep properties of the new cast \& wrought René 65 Ni-based superalloy," 8th International Symposium on Superalloy 718 and Derivatives, Eds. E. Ott, A. Banik, et al., (TMS: Warrendale, PA, USA, 2014), 333-348.

28. D. Locq, P. Caron, S. Raujol, et al., "On the Role of Tertiary $\gamma^{\prime}$ Precipitates in the Creep Behaviour at $700{ }^{\circ} \mathrm{C}$ of a PM Disk Superalloy," Superalloys 2004, Eds. K.A. Green, T.M. Pollock, et al., (TMS: Warrendale, PA, USA, 2004), 179187.

29. A. Soula, "Etude de la déformation intergranulaire au cours $\mathrm{du}$ fluage à haute température d'un superalliage à base de nickel polycristallin", (Ph.D. thesis, Institut National Polytechnique de Grenoble, France, 2010).

30. R. Shewfelt, L. Brown, "High-temperature strength of dispersion- hardened single crystals: I . Experimental results," Philos. Mag., 30 (5) (1974) 1135-1145.

31. M. McLean, "On the threshold stress for dislocation creep in particle strengthened alloys," Acta Metall., 33 (4) (1985) $545-556$.

32. E. Arzt, D.S. Wilkinson, "Threshold stresses for dislocation climb over hard particles: the effect of an attractive interaction," Acta Metall., 34 (10) (1986) 1893-1898.

33. N.K. Sinha, "Short strain relaxation/recovery tests for evaluating creep response of nickel-base superalloys like in738LC," J. Mater. Sci. Lett., 20 (10) (2001) 951-953. 